\title{
Life in a time of COVID: a mixed method study of the changes in lifestyle, mental and psychosocial health during and after lockdown in Western Australians
}

Ranila Bhoyroo ${ }^{1,2,3,4^{*}}$, Paola Chivers ${ }^{1,5}$, Lynne Millar ${ }^{1,2}$, Caroline Bulsara ${ }^{1}$, Ben Piggott ${ }^{3}$, Michelle Lambert ${ }^{3,6}$ and $\operatorname{Jim}$ Codde $^{1,7}$

\begin{abstract}
Background: Since the beginning of the COVID-19 pandemic, the Western Australian government imposed multiple restrictions that impacted daily life activities and the social life. The aim of this study was to examine the effects of COVID-19 lockdown on the community's physical, mental and psychosocial health.

Methods: Approximately 2 months after a three-month lockdown, a cross-sectional study was opened to Western Australian adults for an 8-week period (25th August - 21 October 2020). Participants competed a 25-min questionnaire adapted from the Western Australia Health and Wellbeing Surveillance system. Participants provided information on their socio-demographic status, lifestyle behaviours, mental health, and psychosocial health during and post-lockdown. Open-ended questions explored key issues in greater detail. Changes between the lockdown and post-lockdown period were assessed using Wilcoxon signed rank test and One-Sample Kolmogorov-Smirnov Normal tests as appropriate. Sex differences were examined using the Mann-Whitney $U$ test. A content analysis approach examined responses to the open-ended questions with frequencies and variations in responses determined using Chi-Square tests.

Results: A total of 547 complete responses were obtained. Compared to post-lockdown period, lockdown was associated with a significantly lower levels of physical activity, poorer mental well-being and sense of control over one's life, and a higher level of loneliness. Similarly, during lockdown, there was a significantly higher consumption of junk food, soft drinks and alcoholic drinks but no change in fruit and vegetable intake. Participants recalled health campaigns on hand washing and social distancing and there was a retrospective view that more timely and informative campaigns on physical activity, nutrition and mental well-being should have been available during lockdown
\end{abstract}

\footnotetext{
* Correspondence: ranila.bhoyroo@nd.edu.au

${ }^{1}$ Institute for Health Research, The University of Notre Dame Australia, 19

Mouat Street, PO Box 1225, Fremantle, Western Australia 6959, Australia

${ }^{2}$ School of Population Health, Curtin University, Perth, Australia

Full list of author information is available at the end of the article
}

(c) The Author(s). 2021 Open Access This article is licensed under a Creative Commons Attribution 4.0 International License, which permits use, sharing, adaptation, distribution and reproduction in any medium or format, as long as you give appropriate credit to the original author(s) and the source, provide a link to the Creative Commons licence, and indicate if changes were made. The images or other third party material in this article are included in the article's Creative Commons licence, unless indicated otherwise in a credit line to the material. If material is not included in the article's Creative Commons licence and your intended use is not permitted by statutory regulation or exceeds the permitted use, you will need to obtain permission directly from the copyright holder. To view a copy of this licence, visit http://creativecommons.org/licenses/by/4.0/ The Creative Commons Public Domain Dedication waiver (http://creativecommons.org/publicdomain/zero/1.0/) applies to the data made available in this article, unless otherwise stated in a credit line to the data. 
Conclusions: While advice on infection control measures were appropriately provided, there is a need for concurrent health promotional information to help combat the changes in physical, mental and psychosocial wellbeing observed during quarantine to prevent negative health consequences in the community even if there are minimal effects of the pandemic itself.

Keywords: Depression, Stress, Loneliness, Nutrition, Social isolation, Physical activity, COVID-19, Pandemic, Health promotion

\section{Introduction}

Since the first reports of a novel coronavirus (COVID19 ) in late 2019 , the spread of this virus rapidly progressed into a global pandemic. By May 2021, almost 142 million people had become infected with over 3 million associated deaths [1]. By contrast, the Western Australian community of 2.6 million people had fewer than 1000 infections (most acquired while travelling overseas) and only nine deaths [2].

One of the government's key strategies in minimising the impact of COVID-19 was to rapidly close the national and Western Australia state boarders to travellers in March 2020. The state government also implemented additional restrictions involving the movement of people within the community, which at the highest level of restrictions, included permit-only regional intra-state travel; closure of social venues such as bars, clubs, sporting venues, cinemas, cultural institutions, places of worship; restaurants and cafes were limited to takeaway services; schools were closed; work from home arrangements for many businesses; and weddings, funerals and household visitors were limited to small numbers. In the following months, from mid-May through to late June 2020, the government gradually eased many of these restrictions. As of March 2021, while some restrictions remained in place, the community was operating at some level of normality [3].

A recent systematic review confirmed that quarantine confinement due to infectious disease outbreaks can result in negative psychological outcomes, including insomnia, depression, anxiety, post-traumatic stress, and emotional exhaustion [4]. Similarly, it has been shown that quarantine and isolation can have psychological effects impacting overall lifestyle, level of physical activity and can potentially lead to unhealthy consumption of certain foods and alcohol, all of which carry some longterm effects on cardiovascular disease [5]. Further research reported that sedentarism during home confinement can create detectable changes in muscle wastage within 2 days and that positive energy balance during physical inactivity is linked with fat deposition, associated with systemic inflammation and activation of antioxidant defences, exacerbating muscle loss [5]. Perhaps more importantly, these deleterious effects of inactivity could be diminished by routine exercise practice, although the exercise dose response relationship is currently unknown in this scenario [6]. Numerous studies have reported on the importance of social relationships on healthy nutritional behaviours $[7,8]$ that bode poorly for periods of social distancing and isolation. In their brief paper titled 'Nutritional recommendations for COVID-19 quarantine', the authors describe that quarantine is associated with the interruption of the work routine that can lead to boredom which in turn has been associated with a greater energy intake, as well as the consumption of higher quantities of fats, carbohydrates, and proteins with the associated stresses, pushing people toward overeating, mostly of sugary comfort foods [9]. This is of concern as a dietary pattern characterised by higher intake of processed and unhealthy foods has been shown to be associated with an increased likelihood of higher psychological symptomatology and clinical depression [10, 11].

A growing number of studies have emerged from the COVID-19 period. For example, a large survey conducted in China reported higher prevalence of anxiety and depression in the general population during lockdown [12]. Similarly, a study of non-infected people in both Italy and Israel found higher levels of anxiety and depression during the COVID-19 pandemic compared to the reported prevalence in the general population in previous years [13]. In a survey of Australian adults, Stanton and colleagues reported negative changes in physical activity, sleep, smoking and alcohol intake were associated with higher depression, anxiety and stress symptoms since the onset of COVID-19 [14].

With calls for effective health promotion strategies directed at adopting or maintaining positive health-related behaviours [15-17], the aim of this study was to provide a cross-sectional analysis of the impact of COVID-19 on the wider community's physical, mental and psychosocial health and to identify issues that may persevere after the restrictive measures have been lifted. Particularly to the present study, the term 'psychosocial health' was used as another dimension of health and well-being other than just physical and mental health. This includes level of control, loneliness and resilience to factors that impact on a person's life. The results will help inform current and future health promotion strategies to better assist people maintain their quality of life and healthy lifestyle. 


\section{Methods}

\section{Study design}

Following a request from the state government to rapidly identify the impact of lockdown on the community to inform any future restrictions imposed due to the pandemic, Western Australian residents aged 18 years or older were invited to complete a cross-sectional study using a web-based survey. The survey was open for an 8-week period (between 25th August - 21st October 2020) and commenced approximately 2 months after an enforced community lockdown of 3 months duration (23rd March - 27th June 2020). A mixed method approach using the triangulation design was used.

A priori sample size calculation was conducted based on between group (e.g., five age groups) differences using a medium effect size of $0.31, \alpha=0.05$, and a power $=0.80$ which indicated the need to recruit a minimum sample of 174 participants. This sample size was determined a priori to also enable lockdown and postlockdown response comparisons ( $G$ *Power version 3.1.9.2; 2014).

The survey was promoted through a range of state and local community newspapers and a variety of social media outlets and snowballed through professional linkages. Ethical approval was granted by the University of Notre Dame Human Research Ethics Committee (HREC, 2020-133F).

\section{Questionnaire design}

Participants completed the questionnaire using an online platform (Qualtrics, Provo, UT). The initial page of the survey presented, every potential respondent with an information page that outlined the purpose of the study, estimated duration (25 mins) and anonymity of survey responses. In accordance with HREC requirements, respondents confirmed their consent for their data to be used in the study.

As the main aim of the study was to explore differences in physical, mental and psychosocial behaviours during COVID-19 lockdown restrictions and the postlockdown period, participants were asked to respond to the questions reflecting on both time periods. As a reminder, a list of the lockdown restrictions was provided at the start of the survey and then throughout the survey in the form of a pop-up window to assist recollection.

The survey comprised of questions regarding their basic socio-demographic information, lifestyle behaviours, mental health, and psychosocial health. In addition, several open-ended questions explored these key issues in more detail.

\section{Socio-demographic information}

This series of questions gathered information about the participants that included sex (Male, Female, Other), age (years), locality (Urban vs Rural), level of education (Degree or higher, Diploma or Trade, High School, Did not complete High School), employment status (Employed, Unemployed, Student, Retired, other), and Household income $(<\$ 40,000, \$ 40,000-\$ 100,000,>\$ 100,000)$.

\section{Lifestyle behaviours}

Questions about lifestyle behaviours explored physical activity, sedentary behaviours, nutrition, and alcohol use and were adopted from the Western Australia Health and Wellbeing Surveillance system (WA-HWSS) survey [18].

\section{Mental health}

Mental health was assessed using DASS-21 [19]. DASS21 measures depression, anxiety and stress during the last week via a 21-item questionnaire. Each item is a statement about a negative emotional symptom and is rated by the participant on a $0-3$ scale based on the extent to which they experienced that symptom over the past week. The scores for each of the three scales (i.e., depression, anxiety, and stress) are derived by summing the scores for the seven items that comprise that scale and multiplying the sum by 2 . Higher scores reflect increased severity of the measures. The total score for each scale is converted to a classification (i.e., 'Normal', 'Mild', 'Moderate', 'Severe/Extremely severe') using the DASS Manual [19]. Internal consistency (Cronbach's alpha) is high for each scale (depression $=0.94$, anxiety $=$ 0.87 , Stress $=0.91)$ [20].

Kessler-10 (K-10) is a global measure of psychological stress [21]. It is a 10-item questionnaire scored on a five-point Likert scale resulting in a cumulative score of 10 to 50 which are categorised as 'Likely to be well' [1019], 'Likely to have a mild mental disorder' [20-24], 'Likely to have a moderate mental disorder' [25-29] and 'Likely to have a several mental disorder' [30-50]. The $\mathrm{K}-10$ is a valid and reliable instrument for screening psychological distress at a population level [21]. It is used by Australian Bureau of Statistics as part of their regular data collections [22] and been found to outperform other screening tools amongst an Australian population [23].

\section{Psychosocial health}

The level of perceived lack of control and loneliness were used as measures of psychosocial health. Perceived lack of control was measured using three items adopted from the WA-HWSS survey. The questions were 'How much of the time did you feel a lack of control over your life in general', 'How much of the time did you feel a lack of control over your personal life' and 'How much of the time did you feel a lack of control over your health', all of which captured the response using a five-point Likert 
scale as 'Always', 'Often', 'Sometimes', 'Rarely', or 'Never'.

Loneliness was measured using the validated UCLA three-item scale with responses 'Hardly ever', 'Some of the time', and 'Often' to 12 questions that include 'How often do you feel you lack companionship?', 'How often do you feel left out?', and 'How often you feel isolated from others?' [24]. The UCLA-3 has a reported alpha coefficient of reliability of 0.72 and the internal consistency for a three-item scale was quite good indicating that the items reliably measure loneliness. The questions were scored 1 to 3 , then summed to a score ranging from 3 to 9. Loneliness was subsequently categorized as follows: 'No loneliness' (3, 4), 'Moderate loneliness' (5-7), and 'Severe loneliness' $(8,9)$ [25].

\section{Open ended questions}

In addition to the Likert style survey questions, the participants were asked a series of open-ended question about several topics to explore their responses in greater detail (see Supplementary information). Examples include:

- Thinking back to COVID-19 lockdown, what would you say was the biggest difference made to your physical activity (in other words, any changes to your physical activity preferences, types of physical activity, physical activity intensity, etc.)? Please describe those changes.

- Thinking back to COVID-19 lockdown, what would you say had been the biggest difference you made to your diet (in other words, any changes to your food preferences, types of food, food preparation, cooking, alcohol intake etc.)? Please describe what changed.

- Describe what may have affected (positively and/or negatively) your mental well-being during the COVID-19 lockdown period?

Similarly, the participants were asked three questions regarding their views on the government's health promotion campaign: (a) what health promotion and safety campaigns they recalled from the COVID-19 lockdown period, (b) what personal changes they made in response to these messages and (c) what they felt would be useful in the advent of another lockdown.

\section{Data analysis}

Sociodemographic and survey data were summarised as percentages (\%). As the survey data scores were not normally distributed (Shapiro-Wilk test), group differences in lifestyle behaviours, mental health and psychosocial health for lockdown/post-lockdown periods for all respondents, and males and females separately, was examined using Wilcoxon signed rank test for paired responses.

As most questions required a Likert response, relative changes between the two time periods were calculated to produce a new 3-point measure that indicated whether the response during the lockdown period was 'Increased', 'Same' or 'Decreased' compared to the postlockdown period. This allowed assessment of the impact of the lockdown regardless of the individual's baseline measure. One-Sample Kolmogorov-Smirnov Normal Tests were conducted to assess whether there was an asymmetrical shift in the behaviours between the two periods at the population and sex levels.

No respondents identified sex as 'other' therefore differences between male and female responses were compared using the Mann-Whitney $U$ test. Statistical analysis was performed using SPSS version 26.0 (IBM, Chicago, IL, USA) with results considered statistically significant for $p$ value $<0.05$. Cohen's d (d) effect sizes were calculated from the Z-statistic generated from the Wilcoxon, Kolmogorov-Smirnov or Mann-Whitney test using an online calculator [26].

Quantitative content analysis was undertaken for the open-ended question responses with up to three unique points per question being extracted from each respondent. The exact wording of the extracted points was themed and assigned a numerical code to enable frequency analysis based on the multiple responses to each question [27]. This was descriptively described by simple frequency analysis and then variations between subpopulations of the study population determined by Chisquare analysis.

\section{Results}

\section{Participants}

A total of 793 people indicated their consent to participate in the study. Following exclusion of those participants who were not residents of Western Australia and those who provided consent to participate but did not respond to any questions, 547 participants (69\%) were included in the study. As only one participant reported testing positive for COVID-19, they were removed from this study analysis resulting in a final sample of 546 respondents. As summarized in Table 1, the majority of respondent were aged 45 years or over, female, university educated, lived within the metropolitan area, employed, and had a household income of at least $\$ 100,000$.

\section{Changes in physical activity}

Levels of physical activity during the lockdown period (65\%) was significantly lower compared to the postlockdown (78\%) period and this was consistent for both males and females (Table 2). While there was an overall shift to lower levels of physical activity during lockdown, 
Table 1 Socio-demographic information of participants

\begin{tabular}{|c|c|}
\hline Characteristics & $\%$ \\
\hline \multicolumn{2}{|l|}{ Age (546) } \\
\hline $18-24$ & 11.9 \\
\hline $25-34$ & 13.6 \\
\hline $35-44$ & 14.8 \\
\hline $45-54$ & 20.5 \\
\hline $55-64$ & 21.1 \\
\hline $65+$ & 18.1 \\
\hline \multicolumn{2}{|l|}{ Sex (540) } \\
\hline Male & 25.4 \\
\hline Female & 74.6 \\
\hline \multicolumn{2}{|l|}{ Residential location (544) } \\
\hline Urban & 87.7 \\
\hline Rural & 12.3 \\
\hline \multicolumn{2}{|l|}{ Education (294) } \\
\hline Bachelor degree or higher & 69.7 \\
\hline Diploma or certificate in Trade/apprenticeship & 18.0 \\
\hline Completed high school & 10.9 \\
\hline Did not complete high school & 1.4 \\
\hline \multicolumn{2}{|l|}{ Household income (265) } \\
\hline Under $\$ 40,000$ & 12.5 \\
\hline$\$ 40,000-\$ 100,000$ & 37.0 \\
\hline$\$ 100,000$ and above & 50.6 \\
\hline \multicolumn{2}{|l|}{ Employment during lockdown (291) } \\
\hline Employed (Inc self-employment) & 64.9 \\
\hline Unemployed & 6.9 \\
\hline Student & 6.9 \\
\hline Retired & 17.2 \\
\hline Other & 4.1 \\
\hline
\end{tabular}

Note. The number of respondents $(n)$ for each characteristic is provided in brackets this finding was not universal. One-third (34\%) of respondents reduced their activity during lockdown, but $15 \%$ reported increased activity (Table 3 ). This effect was similar in both sexes. The reasons underpinning this diversity of response are reflected in the responses to the question "What would you say was the biggest difference made to your physical activity?" (Table 4). The need to change their physical activity routines was the most reported impact of the lockdown.

Change of activity from swimming to the walking. (23 yo male)

Compared to those who decreased their level of physical activity during lockdown, many that reported increased level of physical activity felt they had more time to do so $\left(x^{2}=\right.$ 69.33, $p<0.001, n=391, d=0.93)$ and that it helped their mental health $\left(\chi^{2}=22.45, p<0.001, n=391, d=0.49\right)$ :

Not having the commute to work in the morning meant I had an hour to do home workout using a fitness app before work, without having to wake up any earlier. (25 yo female)

For others, working from home reduced their usual level of physical activity:

As I was working from home, I was sitting more as opposed to being active pre-covid (going up and down stairs, taking public transport, walking). Sitting more translated to being less active. (33 yo female)

Those who decreased their physical activity often did so because of limited options, fear of increased risk of infection, reduced team sports activity, and inability to remain motivated.

I didn't feel I had the desire to exercise while my yoga studio was closed. There was too much panic

Table 2 Self-reported level of physical activity during and after the lockdown

\begin{tabular}{|c|c|c|c|c|c|c|c|c|c|c|c|c|}
\hline & \multicolumn{4}{|c|}{ Persons } & \multicolumn{4}{|c|}{ Males } & \multicolumn{4}{|c|}{ Females } \\
\hline & \multicolumn{2}{|c|}{ Lockdown } & \multicolumn{2}{|c|}{ post-lockdown } & \multicolumn{2}{|c|}{ Lockdown } & \multicolumn{2}{|c|}{ post-lockdown } & \multicolumn{2}{|c|}{ Lockdown } & \multicolumn{2}{|c|}{ post-lockdown } \\
\hline & $\bar{n}$ & $\%$ & $n$ & $\%$ & $n$ & $\%$ & $n$ & $\%$ & $n$ & $\%$ & $n$ & $\%$ \\
\hline Very active & 40 & 8.8 & 55 & 12.0 & 9 & 8.0 & 16 & 14.0 & 31 & 9.1 & 39 & 11.3 \\
\hline Active & 114 & 25.1 & 130 & 28.3 & 32 & 28.6 & 38 & 33.3 & 82 & 24.0 & 92 & 26.6 \\
\hline Moderately active & 141 & 31.1 & 175 & 38.0 & 31 & 27.7 & 36 & 31.6 & 110 & 32.2 & 139 & 40.2 \\
\hline Not very active & 119 & 26.2 & 83 & 18.0 & 27 & 24.1 & 22 & 19.3 & 92 & 26.9 & 61 & 17.6 \\
\hline Not active at all & 40 & 8.8 & 17 & 3.7 & 13 & 11.6 & 2 & 1.8 & 27 & 7.9 & 15 & 4.3 \\
\hline Total & 454 & 100.0 & 460 & 100.0 & 112 & 100.0 & 114 & 100.0 & 342 & 100.0 & 346 & 100.0 \\
\hline Wilcoxon sign ranked test $(Z)$ & \multicolumn{4}{|c|}{$-5.48^{* *}, d=0.37$} & \multicolumn{4}{|c|}{$-3.56^{* * *}, d=0.49$} & \multicolumn{4}{|c|}{$-4.18^{* * *}, d=0.32$} \\
\hline
\end{tabular}


Table 3 Relative change in physical activity during lockdown compared to the post-lockdown period

\begin{tabular}{|c|c|c|c|c|c|c|}
\hline & \multicolumn{2}{|c|}{ Persons } & \multicolumn{2}{|c|}{ Males } & \multicolumn{2}{|c|}{ Females } \\
\hline & $n$ & $\%$ & $n$ & $\%$ & $n$ & $\%$ \\
\hline Increase & 70 & 15.4 & 14 & 12.5 & 56 & 16.4 \\
\hline Same & 229 & 50.4 & 57 & 50.9 & 172 & 50.3 \\
\hline Decrease & 155 & 34.1 & 41 & 36.6 & 114 & 33.3 \\
\hline Total & 454 & 100.0 & 112 & 100.0 & 342 & 100.0 \\
\hline Kolmogorov-Smirnov Test $(t)$ & \multicolumn{2}{|c|}{$t=0.27^{* * *}$} & \multicolumn{2}{|c|}{$t=0.28^{* * *}$} & \multicolumn{2}{|c|}{$t=0.26^{* * *}$} \\
\hline
\end{tabular}

around cleanliness and distancing that I felt it best to stay home. (29 yo female)

Lack of motivation. Feeling down. Watching too much tv. (60 yo female)

\section{Changes in food and alcohol consumption}

Consumption of fruit and vegetables remained similar during the lockdown and post-lockdown periods. Of note, the consumption of grain-based products (e.g., bread, cereal and pasta), snack meals, soft drinks and alcohol were all significantly higher during the lockdown period (Table 5). Subanalysis by sex revealed similar changes in the female respondents with an increase in consumption of grain consumption $(Z=-5.24, p<0.001, d=0.45$ ), soft drink (number of days per week: $Z=3.16, p=0.002, d=0.26$; number of cups per day: $Z=-3.16, p=0.002, d=0.27)$, take away snack meals $(Z=-2.46, p=0.014, d=0.36)$ and alcohol (number of standard drinks per day: $Z=2.90, p=0.004, d=0.25$ ). For males, a significant increase was reported in the number of times per week they purchased snack foods (pies, burgers, pizza, chicken, or chips from places like McDonalds, Hungry Jacks, Pizza Hut or Red Rooster; $Z=-2.47, p=0.014, d=$ 0.38 ) and the number of days per week they consumed alcohol $(Z=-3.12, p=0.002, d=0.49)$. Comparison between the sexes only revealed a difference in grain consumption $(Z=2.93, p=0.003, d=0.22)$.

Responses most frequently reported to the question "What would you say was the biggest difference you made to your diet (in other words, any changes to your food preferences, types of food, food preparation, cooking, alcohol intake etc.) during the lockdown?" and "What would you say had been the biggest difference you made to your dining practices (e.g., less dining out, more take away food, more food deliveries, etc.)?” are shown in Table 6.

Approximately a quarter of the responses suggested that the lockdown period had little impact on their diet although this was more common in males than females $\left(\chi^{2}=12.40, p<0.001, d=0.34\right)$.

No real change to diet, although I tended to cook more elaborate meals due to having more time. (29 yo male).

Table 4 How lockdown impacted on physical activity by reported change in physical activity levels

\begin{tabular}{|c|c|c|c|c|}
\hline \multirow[b]{2}{*}{ Coded responses } & \multicolumn{3}{|c|}{ Relative change in physical activity (\%) } & \multirow[b]{2}{*}{ Total $(n=562)$} \\
\hline & Increased $(n=89)$ & Same $(n=267)$ & Decreased $(n=202)$ & \\
\hline Routine changed & 45.8 & 33.1 & 21.5 & 31.1 \\
\hline More sedentary & 6.8 & 13.8 & 36.2 & 20.4 \\
\hline Limited options & 1.7 & 18.8 & 27.7 & 19.0 \\
\hline No change & 8.5 & 25.4 & 6.2 & 16.1 \\
\hline Had more time for PA & 33.9 & 9.9 & 0.8 & 10.5 \\
\hline Substitutes for gym & 3.4 & 6.6 & 10.8 & 7.5 \\
\hline Exercised at home & 8.5 & 6.6 & 6.2 & 6.7 \\
\hline Fear of infection reduced PA & - & 5.0 & 8.5 & 5.4 \\
\hline Made more effort PA & 3.4 & 3.9 & 6.9 & 5.1 \\
\hline Social distancing impacted on PA & 15.3 & 5.5 & - & 5.1 \\
\hline Online exercise videos & 5.1 & 3.3 & 5.4 & 4.6 \\
\hline Reduced team sports & - & 4.4 & 4.6 & 3.8 \\
\hline PA helped with $\mathrm{MH}$ & 13.6 & 1.7 & 0.8 & 3.2 \\
\hline Reduced PA over time period & 1.7 & 1.1 & 6.2 & 2.9 \\
\hline Job loss reduced PA & - & 0.6 & 3.1 & 1.3 \\
\hline More infection awareness from PA & - & 0.6 & 2.3 & 1.1 \\
\hline Other & 3.4 & 7.2 & 8.5 & 7.0 \\
\hline
\end{tabular}

Note. Percentages (\%) are based on multiple responses rather than persons 
Table 5 Changes in food and alcohol consumption during lockdown relative to post-lockdown period

\begin{tabular}{|c|c|c|c|c|c|}
\hline & Increased (\%) & Same (\%) & Decreased (\%) & Wilcoxon Sign Rank (Z) & Cohen's $d$ \\
\hline \multicolumn{6}{|l|}{ Daily number of serves (373) } \\
\hline Vegetables & 12.6 & 74.5 & 12.9 & -0.24 & 0.02 \\
\hline Fruit & 14.2 & 73.2 & 12.6 & -0.39 & 0.04 \\
\hline Grain & 22.0 & 69.4 & 8.6 & $-4.83^{* * *}$ & 0.36 \\
\hline Meat & 13.1 & 78.8 & 8.0 & -1.70 & 0.18 \\
\hline Snack meals per week (372) & 20.4 & 66.7 & 12.9 & $-3.35^{* * *}$ & 0.25 \\
\hline \multicolumn{6}{|l|}{ Consumption of soft drinks } \\
\hline Days per week (389) & 11.6 & 84.1 & 4.4 & $-3.37^{* * *}$ & 0.24 \\
\hline Cups per day (130) & 23.1 & 67.7 & 9.2 & $3.35^{* * *}$ & 0.24 \\
\hline \multicolumn{6}{|l|}{ Alcohol consumption } \\
\hline Days per week (370) & 35.1 & 55.9 & 8.9 & $-8.31^{* * *}$ & 0.64 \\
\hline Standard drinks per day (363) & 23.1 & 66.4 & 10.5 & $-3.08^{* *}$ & 0.23 \\
\hline
\end{tabular}

Note. Statistical analysis was performed using Wilcoxon Sign Ranked test on unaggregated response data. ${ }^{* *}=p$-value $<0.01 .{ }^{* * *}=p$-value $<0.001$. The number of respondents $(n)$ for each item are provided in brackets

Table 6 Responses most frequently reported to open-ended questions about the impact of lockdown on dietary behaviours

\begin{tabular}{|c|c|c|c|}
\hline & Persons (\%) & Males (\%) & Females (\%) \\
\hline \multicolumn{4}{|c|}{ What were the biggest differences to your diet during lockdown? } \\
\hline$n$ & 466 & 105 & 359 \\
\hline No changes & 26.8 & 40.0 & 22.7 \\
\hline Cooked more & 23.9 & 14.1 & 27.1 \\
\hline Ate less healthy food & 18.6 & 21.2 & 17.8 \\
\hline Drank more alcohol & 16.1 & 12.9 & 17.1 \\
\hline Ate healthier food & 13.5 & 12.9 & 13.4 \\
\hline Consumed more food & 12.7 & 3.5 & 15.6 \\
\hline Had more takeaway & 7.6 & 7.1 & 7.8 \\
\hline Ate less food & 5.9 & 7.1 & 5.6 \\
\hline Drank less alcohol & 3.1 & 1.2 & 3.7 \\
\hline Other & 3.1 & 3.6 & 2.6 \\
\hline \multicolumn{4}{|c|}{ What were the biggest differences to your dining practices during lockdown? } \\
\hline$n$ & 487 & 112 & 373 \\
\hline Ate out less & 48.3 & 49.4 & 48.1 \\
\hline More takeaway & 28.4 & 32.1 & 27.4 \\
\hline More cooking at home & 16.8 & 9.9 & 18.9 \\
\hline No difference & 16.5 & 23.5 & 14.4 \\
\hline More food deliveries & 8.8 & 3.7 & 10.4 \\
\hline Less deliveries due to COVID fear & 6.3 & 6.2 & 6.3 \\
\hline Eat healthier & 4.0 & - & 5.2 \\
\hline More unhealthy food & 2.6 & 3.7 & 1.9 \\
\hline More alcohol & 1.4 & 1.2 & 1.1 \\
\hline Weight gain & 1.4 & 1.2 & 1.5 \\
\hline Other & 4.0 & 7.4 & 3.0 \\
\hline
\end{tabular}

Note. Percentages (\%) are based on number of responses 
Many people reported cooking more often $\left(\chi^{2}=7.48\right.$, $p=0.006, d=0.26)$. Many also reported eating less healthy food with a similar number saying they drank more alcohol, with responses from males and females not detected to be significantly different.

I cooked more comfort food and large meals I could freeze and starting drinking alcohol earlier in the afternoon than before Covid-19. (71 yo female)

More fast food, less home cooked meals. Higher preference for unhealthy foods. (23 yo male)

In response to the question "What would you say was the biggest difference you made to your dining practice during the lockdown?", most people replied that they 'ate out less' (48\%) followed by 'more take away food' (28\%) and more 'home delivery' (9\%). However, as highlighted by the quotes below, the reasons underpinning this change in behaviour varied:

Less dining out... More take away food for the first few months as we wanted to support local businesses however this got quite expensive quickly. (28 yo female)

We avoided supermarkets and enjoyed home delivery by Woolworths. We ceased dining out at restaurants and with friends. (71 yo male)

We got hello fresh delivered during lockdown which we did have before sometimes, but we choose it because we didn't want to go the grocery store and it was easy and healthy. We are out less because of the restaurants closing. (23 yo female)

Almost a fifth of respondents indicated they cooked more at home as a result of the lockdown although this was more commonly reported by females $\left(x^{2}=6.60, p=\right.$ $0.010, \mathrm{~d}=0.24)$.

I used to dine out at least once a week but that stopped when restaurants closed. I cooked a lot more than I had previously and also got food deliveries. I started to get a bit more creative in the kitchen due to some food shortages when people were stockpiling. (31 yo female)

I cooked a lot more roasts as I was home all day and could better monitor the oven. (27 yo female)

The proportion of people who reported increased food deliveries $(8.8 \%)$ was similar to those who claimed to reduce their number of deliveries due to fear of COVID19 (6.3\%).
More deliveries. More take out. (57 yo female)

We didn't want to risk take-away food so had none. (53 yo female)

\section{Changes in mental health and psychosocial health}

Lockdown was associated with a significant increase in self-reported mental disorders with $40 \%$ of respondents reporting mild to severe mental disorders (Kessler-10) compared to $28 \%$ in the post-lockdown period. This effect was observed in both males and females (Table 7). A significant increase in the levels of depression and stress were identified using the DASS-21 instrument, but not for anxiety. At the sex level, only females showed a statistically significant increase in the level of depression across the two time periods (Table 8).

Feedback provided to the question "Describe what may have affected (positively and/or negatively) your mental well-being during the COVID-19 lockdown period?" provide some insights to these changes. From a negative perspective:

Lack of social contact, confinement at home, concern about my own health and that of family members, worry about job security, despair at the mistakes made by governments and irresponsibility, ignorance and selfishness displayed by some people, the sense that the situation was bad and made still worse by foolishness and malice. (52 yo male)

Being locked in a house 100\% of the time with my significant other was "detrimental" to our relationship. We just kept getting on each other's nerves. (41 yo male)

Others reported a positive effect of the lockdown:

Increased physical exercise indoors and outdoors, spending more time more frequently with family, and more time watching videos. I enjoyed [it] all [and it] affected my mental health positively. (30 yo male)

During the lockdown period, significantly fewer respondents (52\%) reported always or usually having control over their general lives compared to $72 \%$ in the post-lockdown period. Similar significant findings were observed in both sexes (Table 9). Control factors described included:

Increased stress due to alarm and panic buying, and sense that society was beginning to destabilise in certain ways. Heightened alertness to the risk of contracting Covid-19. Sense of restriction on movement outside the house. Increased worry over health and future of older relatives and friends. (28 yo male) 
Table 7 Presence of psychological distress using the Kessler Psychological Distress Scale (K10) for persons, males and females

\begin{tabular}{|c|c|c|c|c|c|c|c|c|c|c|c|c|}
\hline & \multicolumn{4}{|c|}{ Persons } & \multicolumn{4}{|c|}{ Males } & \multicolumn{4}{|c|}{ Females } \\
\hline & \multicolumn{2}{|c|}{ Lockdown } & \multicolumn{2}{|c|}{ Post-lockdown } & \multicolumn{2}{|c|}{ Lockdown } & \multicolumn{2}{|c|}{ Post-lockdown } & \multicolumn{2}{|c|}{ Lockdown } & \multicolumn{2}{|c|}{ Post-lockdown } \\
\hline & $n$ & $\%$ & $n$ & $\%$ & $n$ & $\%$ & $n$ & $\%$ & $n$ & $\%$ & $n$ & $\%$ \\
\hline Likely to be well & 208 & 60.5 & 254 & 72.0 & 57 & 67.9 & 66 & 78.6 & 151 & 58.3 & 188 & 70.1 \\
\hline Moderate distress & 50 & 14.5 & 39 & 11.0 & 13 & 15.5 & 6 & 7.1 & 36 & 13.9 & 32 & 11.9 \\
\hline Mild mental disorder & 36 & 10.5 & 22 & 6.2 & 5 & 6.0 & 8 & 9.5 & 31 & 12.0 & 14 & 5.2 \\
\hline Severe mental disorder & 50 & 14.5 & 38 & 10.8 & 9 & 10.7 & 4 & 4.8 & 41 & 15.8 & 34 & 12.7 \\
\hline Total & 344 & 100.0 & 353 & 100.0 & 84 & 100.0 & 84 & 100.0 & 259 & 100.0 & 268 & 100.0 \\
\hline Wilcoxon sign rank (Z) & \multicolumn{4}{|c|}{$-5.21^{* * *}, d=0.41$} & \multicolumn{4}{|c|}{$-2.98 * * d=0.47$} & \multicolumn{4}{|c|}{$-4.49 * * *, d=0.39$} \\
\hline
\end{tabular}

Note. ${ }^{* *}=p$-value $<0.01 ;{ }^{* * *}=p$-value $<0.001 ; d=$ Cohen's D

Missed family milestones (eg. grandchildren's birthdays), difficult to visit mother in Aged Care (long travel time for very short visit). (68 yo female)

Similar significant differences were also observed for the questions about level of control over one's personal life and health for all respondents $(Z=-5.13, p<0.001, d=$ 0.43 ; $Z=-5.81, p<0.001, d=0.50)$, for males $(Z=-$ 2.67, $p=0.008, d=0.46 ; Z=-3.63, p<0.001, d=0.64)$, and females $(Z=-4.41, p<0.001, d=0.43 ; Z=-4.54$, $p<0.001, d=0.44)$.

In addition to increased sense of a lack of control over their lives, almost $70 \%$ of respondents reported moderate to severe levels of loneliness during the lockdown compared to $55 \%$ during the post-lockdown period. Similar impact was observed in both males and females (Table 10). Factors impacting this sense of loneliness is articulated below:

Table 8 Presence of Depression, Anxiety and Stress Scale (DASS-21) for persons, males and females

\begin{tabular}{|c|c|c|c|c|c|c|c|c|c|c|c|c|}
\hline & \multicolumn{4}{|c|}{ Depression } & \multicolumn{4}{|c|}{ Anxiety } & \multicolumn{4}{|c|}{ Stress } \\
\hline & \multicolumn{2}{|c|}{ Lockdown } & \multicolumn{2}{|c|}{ Post-lockdown } & \multicolumn{2}{|c|}{ Lockdown } & \multicolumn{2}{|c|}{ Post-lockdown } & \multicolumn{2}{|c|}{ Lockdown } & \multicolumn{2}{|c|}{ Post-lockdown } \\
\hline & $\%$ & $n$ & $\%$ & $n$ & $\%$ & $n$ & $\%$ & $n$ & $\%$ & $n$ & $\%$ & $n$ \\
\hline \multicolumn{13}{|l|}{ Persons } \\
\hline Normal & 193 & 65.0 & 216 & 72.2 & 237 & 80.1 & 246 & 82.0 & 226 & 80.7 & 252 & 85.1 \\
\hline Mild & 32 & 10.8 & 30 & 10.0 & 16 & 5.4 & 19 & 6.3 & 20 & 7.1 & 15 & 5.1 \\
\hline Moderate & 36 & 12.1 & 26 & 8.7 & 14 & 4.7 & 9 & 3.0 & 19 & 6.8 & 9 & 3.0 \\
\hline Severe & 10 & 3.4 & 10 & 3.3 & 10 & 3.4 & 9 & 3.0 & 14 & 5.0 & 17 & 5.7 \\
\hline Extremely severe & 26 & 8.8 & 17 & 5.7 & 19 & 6.4 & 17 & 5.7 & 1 & 0.4 & 3 & 1.0 \\
\hline Wilcoxon sign rank (Z) & \multicolumn{4}{|c|}{$-2.71^{* *}, d=0.22$} & \multicolumn{4}{|c|}{$-0.98, d=0.08$} & \multicolumn{4}{|c|}{$-1.99 *, d=0.17$} \\
\hline \multicolumn{13}{|l|}{ Males } \\
\hline Normal & 46 & 65.7 & 46 & 65.7 & 59 & 84.3 & 60 & 84.5 & 55 & 84.6 & 60 & 85.7 \\
\hline Mild & 6 & 8.6 & 6 & 8.6 & 3 & 4.3 & 5 & 7.0 & 6 & 9.2 & 3 & 4.3 \\
\hline Moderate & 9 & 12.9 & 9 & 12.9 & 3 & 4.3 & 1 & 1.4 & 2 & 3.1 & 3 & 4.3 \\
\hline Severe & 2 & 2.9 & 2 & 2.9 & - & 0.0 & 1 & 1.4 & 2 & 3.1 & 3 & 4.3 \\
\hline Extremely severe & 7 & 10.0 & 7 & 10.0 & 5 & 7.1 & 4 & 5.6 & - & 0.0 & 1 & 1.4 \\
\hline Wilcoxon sign rank ( $Z$ ) & \multicolumn{4}{|c|}{$-1.89, d=0.32$} & \multicolumn{4}{|c|}{$-0.30, d=0.05$} & \multicolumn{4}{|c|}{$-0.81, d=0.14$} \\
\hline \multicolumn{13}{|l|}{ Females } \\
\hline Normal & 146 & 64.6 & 163 & 71.8 & 177 & 78.7 & 185 & 81.1 & 170 & 79.4 & 191 & 84.9 \\
\hline Mild & 26 & 11.5 & 24 & 10.6 & 13 & 5.8 & 14 & 6.1 & 14 & 6.5 & 12 & 5.3 \\
\hline Moderate & 27 & 11.9 & 18 & 7.9 & 11 & 4.9 & 8 & 3.5 & 17 & 7.9 & 6 & 2.7 \\
\hline Severe & 8 & 3.5 & 8 & 3.5 & 10 & 4.4 & 8 & 3.5 & 12 & 5.6 & 14 & 6.2 \\
\hline Extremely severe & 19 & 8.4 & 14 & 6.2 & 14 & 6.2 & 13 & 5.7 & 1 & 0.5 & 2 & 0.9 \\
\hline Wilcoxon sign rank (Z) & \multicolumn{4}{|c|}{$-2.09^{*}, d=0.20$} & \multicolumn{4}{|c|}{$-0.87, d=0.08$} & \multicolumn{4}{|c|}{$-1.82, d=0.18$} \\
\hline
\end{tabular}


Table 9 Response summary for question: How much of the time did you feel in control over your life in general?

\begin{tabular}{|c|c|c|c|c|c|c|c|c|c|c|c|c|}
\hline & \multicolumn{4}{|c|}{ Persons } & \multicolumn{4}{|c|}{ Males } & \multicolumn{4}{|c|}{ Females } \\
\hline & \multicolumn{2}{|c|}{ Lockdown } & \multicolumn{2}{|c|}{ Post-lockdown } & \multicolumn{2}{|c|}{ Lockdown } & \multicolumn{2}{|c|}{ Post-lockdown } & \multicolumn{2}{|c|}{ Lockdown } & \multicolumn{2}{|c|}{ Post-lockdown } \\
\hline & $n$ & $\%$ & $n$ & $\%$ & $n$ & $\%$ & $n$ & $\%$ & $n$ & $\%$ & $n$ & $\%$ \\
\hline Always & 68 & 23.0 & 92 & 30.9 & 20 & 28.2 & 25 & 35.2 & 48 & 21.4 & 67 & 29.9 \\
\hline Often & 85 & 28.7 & 122 & 40.9 & 20 & 28.2 & 26 & 36.6 & 65 & 29.0 & 96 & 42.9 \\
\hline Sometimes & 76 & 25.7 & 50 & 16.8 & 17 & 23.9 & 13 & 18.3 & 58 & 25.9 & 36 & 16.1 \\
\hline Rarely & 49 & 16.6 & 25 & 8.4 & 8 & 11.3 & 5 & 7.0 & 41 & 18.3 & 20 & 8.9 \\
\hline Never & 18 & 6.1 & 9 & 3.0 & 6 & 8.5 & 2 & 2.8 & 12 & 5.4 & 7 & 3.1 \\
\hline Total & 296 & 100.0 & 298 & 100.0 & 71 & 100.0 & 71 & 100.0 & 224 & 100.0 & 226 & 100.0 \\
\hline Wilcoxon sign rank (Z) & \multicolumn{4}{|c|}{$-14.91^{* * *}, d=1.54$} & \multicolumn{4}{|c|}{$-7.32^{* * *}, d=1.56$} & \multicolumn{4}{|c|}{$-12.98^{* * *}, d=1.55$} \\
\hline
\end{tabular}

Note. ${ }^{* * *}=p$-value $<0.001 ; d=$ Cohen's $\mathrm{D}$

Unable to meet with friends and family. Unable to visit family back in my country of origin, hearing and reading bad news about [the] pandemic, feeling lonely, working at the University campus which was deserted, no extra activities after work. (39 yo female)

\section{Awareness and impact of health and safety campaigns}

Analysis of the open-ended question regarding what health promotion and safety campaigns the respondent's recalled during the COVID-19 lockdown period revealed that the most common health messages recalled involved hand hygiene and social distancing, with most frequent responses summarised in Table 11. Almost a quarter of respondents did not recall seeing any health and safety campaigns from the lockdown period. Over a third of respondents claimed that they did not change any of their personal behaviours because of the health promotional material they had observed although many reported they washed their hands, used sanitizer, and observed social distancing.

None, we've always had clean practices. (59 yo male)

I stopped listening to media, government and experts as their data has been shown to constantly conflict and later turn out to be false, an over statement or misstated to the public to create fear. (45 yo male)

In response to the question about what health promotion or safety material they would like in the advent of another outbreak, many wanted better and timelier information about the outbreak with others requesting more physical, nutritional, and mental health support information.

I think overall the information is already out there. During the first lock down governments were struggling to organise their messages as they were naturally making it up as they went along. They are a lot better at staying on message now and talking plainly and openly about what happens. (63 yo male)

Just make the requirements clear and easily found. Keep them updated at the same location rather than putting changes or new requirements in announcements. (39 yo male)

When those changes identified as significantly different between the lockdown and post-lockdown period were further analysed by those who either increased or decreased their behaviours, some significant variations were observed. For example, as shown in Table 11,

Table 10 Level of loneliness for persons, males and females

\begin{tabular}{|c|c|c|c|c|c|c|c|c|c|c|c|c|}
\hline & \multicolumn{4}{|c|}{ Persons } & \multicolumn{4}{|c|}{ Males } & \multicolumn{4}{|c|}{ Females } \\
\hline & \multicolumn{2}{|c|}{ Lockdown } & \multicolumn{2}{|c|}{ Post-lockdown } & \multicolumn{2}{|c|}{ Lockdown } & \multicolumn{2}{|c|}{ Post-lockdown } & \multicolumn{2}{|c|}{ Lockdown } & \multicolumn{2}{|c|}{ Post-lockdown } \\
\hline & $n$ & $\%$ & $n$ & $\%$ & $n$ & $\%$ & $n$ & $\%$ & $n$ & $\%$ & $n$ & $\%$ \\
\hline Not lonely & 91 & 30.8 & 135 & 45.2 & 20 & 28.2 & 35 & 48.6 & 71 & 31.8 & 100 & 44.2 \\
\hline Moderately & 90 & 30.5 & 77 & 25.8 & 27 & 38.0 & 20 & 27.8 & 62 & 27.8 & 57 & 25.2 \\
\hline Severely & 114 & 38.6 & 87 & 29.1 & 24 & 33.8 & 17 & 23.6 & 90 & 40.4 & 69 & 30.5 \\
\hline Total & 295 & 100.0 & 299 & 100.0 & 71 & 100.0 & 72 & 100.0 & 223 & 100.0 & 226 & 100.0 \\
\hline Wilcoxon sign rank (Z) & \multicolumn{4}{|c|}{$-5.47^{* * *}, d=0.46$} & \multicolumn{4}{|c|}{$-3.55^{* * *}, d=0.62$} & \multicolumn{4}{|c|}{$-4.41^{* * *}, d=0.43$} \\
\hline
\end{tabular}

Note. ${ }^{* * *}=p$-value $<0.001 ; d=$ Cohen's D 
Table 11 Most frequent reported responses to open-ended questions about health promotion campaigns

\begin{tabular}{|c|c|c|c|c|c|}
\hline & Persons (\%) & Increase (\%) & Decrease (\%) & $x^{2}$ & d \\
\hline \multicolumn{6}{|l|}{ Recall of health promotion campaigns (411) } \\
\hline Washing hands & 51.7 & & & & \\
\hline Social distancing & 39.6 & & & & \\
\hline By change in physical activity & & 52.4 & 31.6 & $4.96^{*}$ & 0.41 \\
\hline By change in daily alcohol consumption & & 36.0 & 66.7 & $4.86^{*}$ & 0.48 \\
\hline By change in number of standard drinks per day & & 29.2 & 57.9 & $6.03^{*}$ & 0.62 \\
\hline Can't recall any & 23.5 & & & & \\
\hline Mental health & 13.9 & & & & \\
\hline Coughing into elbow & 9.6 & & & & \\
\hline \multicolumn{6}{|l|}{ Personal changes in behaviour (353) } \\
\hline No change in behaviour & 38.2 & & & & \\
\hline By change in stress levels (DASS-21) & & 33.3 & 66.7 & $4.50^{*}$ & 0.32 \\
\hline Washed hands properly & 33.6 & & & & \\
\hline Socially distanced & 33.2 & & & & \\
\hline By change in physical activity & & 44.7 & 21.6 & $6.46^{*}$ & 0.49 \\
\hline By change in number of standard drinks per day & & 22.7 & 54.5 & $7.77^{*}$ & 0.72 \\
\hline Used sanitizer & 18.2 & & & & \\
\hline Coughed into elbow & 5.0 & & & & \\
\hline \multicolumn{6}{|l|}{ Suggestions for future safety or health promotion campaigns (244) } \\
\hline No need for anything different & 30.5 & & & & \\
\hline Better access to timely WA specific information & 20.0 & & & & \\
\hline More about how to maintain physical, nutritional, and mental well-being & 15.2 & & & & \\
\hline By change in grain consumption & & 22.0 & 0.0 & $4.66^{*}$ & 0.59 \\
\hline Clearer direction as to when and where to wear masks & 12.9 & & & & \\
\hline
\end{tabular}

Note. Percentages (\%) are based on multiple responses rather than persons. The total number of responses $(n)$ for each aspect are provided in brackets. ${ }^{*}=p$ value $<0.05 ; \mathrm{x}^{2}=$ Chi Square statistic; $d=$ Cohen's D

differences in recall of health promotion campaigns were observed between those who increased or decreased their level of physical activity, daily alcohol intake or the number of standard drinks per day.

From this analysis, it seems those who increased their levels of physical activity were more aware of the need to socially distance from others, as were those who reduced their alcohol intake by reducing the number of days they drank or the number of standard drinks they consumed per day. Similarly, more people who reported lower stress levels during the COVID-19 lockdown felt the need to change their behaviours. Of those that observed social distancing, many increased their level of physical activity or reduced their level of alcohol consumption. Of those who suggested campaigns in the advent of a future lockdown, the only sub-group that showed a statistically significant difference to the general respondents were those who increased their grain intake. Within this group, they felt additional information about how to maintain their physical, nutritional, and mental well-being was needed.
[Recalled] Physical activity one from the government and lifeline doing their thing for mental health. (21 yo female)

[Behavioural change] Spatial distancing, Washing hands properly and often, Coughing into elbow, Avoiding contact, Maintaining exercise. (60 yo, unknown)

[Future information suggestion] Information for people with respiratory conditions - more information so we don't get anxious. (41 yo female)

\section{Discussion}

In the present study, the effect of a three-month lockdown, aimed at reducing the spread of COVID-19, on the community's physical activity, nutrition and mental well-being was examined. The largest impact, as measured by effect size, was the sense of loss of control respondents had over their lives, followed by an increase in loneliness and alcohol consumption (medium effects). 
Even though the effects were small, significant decrease in physical activity and increase in the utilisation of snack foods and soft drinks were observed. When looking at mental well-being, while there was a medium effect of lockdown on psychological distress (Kessler-10), only a small effect was observed on the levels of selfreported depression and stress (DASS-21), and interestingly, no observed significant change in community anxiety levels. Taken together, for a community that had very little impact from the disease itself when compared to other countries globally, significant negative changes in physical activity, nutrition, mental and lifestyle were observed in residents of Western Australia during lockdown.

The design of this study does not allow comparison of the results obtained between the lockdown and postlockdown period to those of a 'normal' baseline period. To address this issue, results from the current study were compared to results from the Western Australian Department of Health's Health and Wellbeing Surveillance System (HWSS) from which many of the questions in the current study were drawn [18]. In recent HWSS reports $[28,29]$ survey responses obtained during March - May 2020 were compared to responses from the same three-month period during 2015-2019 (baseline). Although there were differences in the age profiles of the HWSS and the current study, the findings were similar during lockdown for fruit and vegetable consumption, physical activity, alcohol consumption, psychological distress, and level of control over one's life. This suggested that the data obtained during the post-lockdown period of the current study does reflect the community norms. Examination of the HWSS data for the full 2019 period suggests however that while physical activity, fruit, vegetable, and alcohol consumption had returned to preCOVID levels, the sense of control over one's life and level of psychological distress had not fully returned to their pre-COVID levels [28]. The delayed return of mental well-being to pre-COVID levels may not be surprising given the continued state of awareness of the disease around the world and some local restrictive measures that were still in place during the survey period. This observation is in keeping with analysis of calls to a mental health helpline both prior to, during (increased peak) and following full lockdown (heightened from preCOVID period) [30].

The sense of loneliness during COVID-19 lockdown as observed in the current study is similar to other communities [31-33], and shown to be associated with adverse mental health effects such as depression, anxiety, and stress-related disorders [33]. This may account for some of the increased level of self-reported depression and stress seen in this study, as loneliness has been estimated to contribute up to $18 \%$ of depression in a longitudinal study [34]. It remains unclear why anxiety levels were not altered during lockdown in the present study as others have found increases in all three mental health measures using the same instrument in a webbased surveys of the Ecuadorian and Spanish populations $[35,36]$. Of note, the COVID-19 related death rate in these countries were 20-100 times greater than in Australia [37]. Increases in depression and anxiety in the population have been shown during COVID-19 and other epidemics $[9,38]$, and the effects can persist for at least a year [39]. Despite the low level of community infection in Western Australia, this study still identified a negative impact in mental well-being on a sizeable proportion of the community during the COVID-19 lockdown that remained evident several months after most of the restrictions had been lifted.

The relationship between increased levels of loneliness, depression and alcohol consumption have also been reported. For example, a study of over 6500 older adult Americans observed strong associations between experiencing depression, anxiety, or loneliness and increased alcohol consumption in the past week, with a dose-response relationship between overall mental health symptom burden and drinking either more or less in the past week than before the COVID-19 pandemic [40]. While the overall level of alcohol drinking in the current study was similar in both time periods, about a quarter to a third of respondents reported increasing the amount and/or the frequency of consumption during the lockdown period. This was offset by most drinking behaviours remaining unchanged, or in some cases, reducing. Similar findings have been reported in another study where there was an overall slight reduction in alcohol consumption in French speaking Belgians despite almost a third of people reporting increased alcohol intake [41]. Similar zero net change in population level drinking has been reported in other countries [42-44] which suggests there are multiple factors that impact on a person's drinking behaviour during period of social isolation, including drinking culture [45].

As in many countries, the Western Australian government responded early to the virus outbreak by implementing several restrictions, some of which had a direct bearing on the community's ability to engage in their normal physical activity routines. These included closure of gyms, social distancing, use of masks and limiting many class-based exercise sessions to one-on-one, and limiting outdoor exercise to $1 \mathrm{~h}$ per day. Consequently, the level of physical activity reported in the current survey significantly reduced during the lockdown which is consistent with findings reported from previous studies $[46,47]$.

Despite the overall reduction in community physical activity levels, many respondents maintained similar 
levels of physical activity through the lockdown period, with about a third reducing their levels, while $15 \%$ increased them relative to the post-lockdown period. Some understanding of this diverse response comes from a small Canadian qualitative study that identified four themes on how the participants perceived COVID-19 lockdown impacted them: (1) Disruption to Daily Routines, (2) Changes in Physical Activity, (3) Balancing Health, and (4) Family Life [48]. Each of these themes encapsulated both positive and negative effects of the pandemic on physical activity with, as an example, some participants modifying their physical activity routines during the pandemic to maintain levels, while others had difficulty adapting and hence decreased their levels of activity. In the current study, similar differences were identified in the way the respondents perceived the impact of the lockdown in their physical activity with many of those who reduced their activity citing they had limited options, fear of becoming infected and loss of motivation over time. On the other hand, those that increased their activity levels reported they had more time to exercise, managed to adapt their routines and believed it would aid their mental health. In addition, our survey respondents noted that many gyms adapted classes to an online platform to retain members and to meet member needs. Interestingly, a Saudi Arabian study showed there was a significant increase in health-related quality of life and reduced psychological distress in adults who were physically active compared with inactive participants regardless of the level of impact of COVID19 on their lives [49]. This study corroborates the mental health benefits of physical activity during such a pandemic [50] and suggests that finding the right health promotional message to encourage members of the community to maintain or increase their level of physical activity could have positive outcomes on their mental well-being during periods of great challenge.

In keeping with the range of dietary behaviours reported in the current study, a recent review of dietary changes during COVID-19 found that lockdown both negatively and positively impacted dietary practices globally [51]. In addition, a number of respondents also noted that they had selected local restaurant takeaways to support the community and local businesses. Favourable changes in dietary habits included increases in fresh produce, home cooking and reductions in comfort food and alcohol consumption whilst negative diet habits included reduction in fresh produce, an increase in comfort foods including sweets, fried food, snack foods, and processed foods. Negative food habits are associated with poorer lifestyle outcomes including weight gain, mental health issues, and limited physical activity. With reports of a relationship between diet and mental health in adolescents [52] and adults [53], and alcohol consumption and mental health [40], greater efforts are required to address the large number of people who in the current study reported eating less healthy foods and drinking more alcohol.

With the clear interaction between loneliness, physical activity, dietary behaviours and mental well-being, it is interesting to note that the most common health promotion information recalled by the respondents in the current study was limited to hand hygiene and social distancing, with almost a quarter of respondents not recalling any campaign. Alarmingly, almost $40 \%$ of people claimed that their behaviours did not change during this period despite seeing a health campaign, although in some cases, this is because they already observed the requirement. While most people did not see the need for any new or additional health promotional requirements in the advent of a subsequent lockdown, one in five people wanted better access to relevant and timely information and only $15 \%$ wanted better information about how to improve their levels of physical activity, dietary behaviours and mental wellbeing. This is at odds with the emerging view of the close relationship between mental well-being, physical activity and dietary behaviours, especially during a pandemic that greatly increases the level of social isolation and high levels of loneliness. The Western Australian Department of Health has a Health Promotion Strategic Plan that outlines a strategy to address obesity, healthy eating, physical activity, tobacco smoking, alcohol consumption and preventable injuries [54]. Despite this, its social marketing campaigns during 2020 focused on COVID-19, sexual health, needle and syringe safety and urgent primary care services [55]. For the COVID-19 campaigns, the key messages pertained to social distancing, hand hygiene and 'stay at home if sick'. The findings of this study suggest that extending the current health promotion campaigns to include and emphasize the on-going need and benefits of the wider range of topics as outlined in the Department's Health Promotion Strategic Plan would be effective in encouraging health promoting behaviours.

The findings from this cross-sectional study provided useful insights about changes in daily life and social activities in Western Australia during the COVID-19 lockdown period. In particular, residents reported a decrease in physical activity level, increased loneliness, less control over life and health, poor nutritional intake (snacks and alcoholic drinks) and increased states of depression and stress. The inclusion of open-ended responses provided a deeper understanding of these key changes. However, several limitations were noted. While the study comprised of a large number of respondents, the use of convenience sampling method may have some risk of bias and limit the generalizability of results. The 
data were collected using an online questionnaire and was therefore inaccessible to people who did not have a device with internet services to complete the survey. Although the study was conducted shortly after the lockdown period, self-reported responses are still subject to recall bias. Finally, the paired response to questions during both the COVID-19 lockdown and post-lockdown period increased the statistical power of the study, but as the study was of cross-sectional design, inference from causal relationships could not be drawn. Given that confinement was undertaken at home, characteristics of the house and surroundings may influence physical, mental and psychosocial health and this would be an interesting aspect to consider in future research.

\section{Conclusion}

An investigation of a 3 month lockdown in 2020 due to COVID-19 on the physical, mental and psychosocial aspects showed significant negative changes in physical activity, nutrition, alcohol and soft drink consumption, mental well-being and psychosocial health in the Western Australian community. While there is obvious need for governments to disseminate information about how individuals can protect themselves from infectious disease such as COVID-19, it is also clear that they need to provide timely and accurate information about the disease in a balanced way to help improve well-being. These programs need to be complimented with effective health promotion strategies directed at adopting or maintaining positive health related behaviours and ongoing evaluation to ensure they are targeted to all sections of the community. Such strategies need to address the challenges of social isolation, lifestyle changes, physical and nutritional habits.

\section{Abbreviations}

HREC: Human Resource Ethics Committee; WA-HWSS: Western Australia Health and Wellbeing Surveillance system; DASS-21: Depression Anxiety Stress Scales; K-10: Kessler Psychological Distress Scale (K-10)

\section{Supplementary Information}

The online version contains supplementary material available at https://doi. org/10.1186/s12889-021-11971-7

Additional file 1. Supplementary file: Questionnaire used to collect data for the COVID-19 study in Western Australia. Supplementary file description: The file can be viewed using adobe acrobat reader.

\section{Acknowledgements}

We would like to thank the participants of the study. We would also like to thank our two community representatives (Jim and Mich) who provided input to the study development and questionnaire design.

\section{Authors' contributions}

$\mathrm{JC}$ led the study and developed the initial manuscript. All authors contributed to study development and reviewing of manuscripts. RB contributed to ethics application, data collection and analysis and manuscript writing. JC, PC and CB contributed to data analysis. $\mathrm{LM}, \mathrm{BP}$ and
ML provided input to questionnaire design. All authors read and approved the final manuscript.

\section{Funding}

This study was funded by a Western Australia Government grant through the Department of Jobs, Tourism, Science and Innovation.

Availability of data and materials

All data analyzed during this study are available from the corresponding author on request and subject to appropriate HREC approvals.

\section{Declarations}

Ethics approval and consent to participate

The study was approved by the HREC at The University of Notre Dame Australia (Ref: 2020-133F). All protocols are carried out in accordance with relevant guidelines and regulations. In accordance with HREC requirements, respondents provided informed consent, were informed that they were free to withdraw from the study at any time and confirmed their consent for their data to be used in the study.

Consent for publication

Not applicable.

\section{Competing interests}

The authors declare that they have no competing interests.

\section{Author details}

'Institute for Health Research, The University of Notre Dame Australia, 19 Mouat Street, PO Box 1225, Fremantle, Western Australia 6959, Australia. ${ }^{2}$ School of Population Health, Curtin University, Perth, Australia. ${ }^{3}$ School of Health Sciences, The University of Notre Dame Australia, Perth, Australia. ${ }^{4}$ Disciplines of Psychology and Exercise Science, Murdoch University, Perth, Australia. ${ }^{5}$ School of Medical and Health Sciences, Edith Cowan University, Perth, Australia. ${ }^{6}$ Injury Matters, Perth, Australia. ${ }^{7}$ Division of Obstetrics \& Gynaecology, The University of Western Australia, Perth, Australia.

Received: 22 May 2021 Accepted: 8 October 2021

Published online: 26 October 2021

\section{References}

1. World Health Organization. 2021 [Available from: https://www.who.int/. Accessed 12 May 2021.

2. Governement of Western Australia. 2021 [Available from: https://www.wa. gov.au/. Accessed 12 May 2021.

3. Parliament of Western Australia. 2021. Available from https://www.parlia ment.wa.gov.au/WebCMS/WebCMS.nsf/index. Accessed 12 May 2021.

4. Brooks SK, Webster RK, Smith LE, Woodland L, Wessely S, Greenberg N, et al. The psychological impact of quarantine and how to reduce it: rapid review of the evidence. Lancet. 2020;395(10227):912-20. https://doi.org/10.1016/ S0140-6736(20)30460-8.

5. Mattioli AV, Ballerini Puviani M, Nasi M, Farinetti A. COVID-19 pandemic: the effects of quarantine on cardiovascular risk. Eur J Clin Nutr. 2020;74(6):852-5. https://doi.org/10.1038/s41430-020-0646-z.

6. Narici M, De Vito G, Franchi M, Paoli A, Moro T, Marcolin G, et al. Impact of sedentarism due to the COVID-19 home confinement on neuromuscular, cardiovascular and metabolic health: physiological and pathophysiological implications and recommendations for physical and nutritional countermeasures. Eur J Sport Sci. 2020;21(4):1-22. https://doi.org/10.1080/1 7461391.2020 .1761076

7. Conklin Al, Forouhi NG, Surtees P, Khaw K-T, Wareham NJ, Monsivais P. Social relationships and healthful dietary behaviour: evidence from over-50s in the EPIC cohort, UK. Soc Sci Med. 2014;100:167-75. https://doi.org/10.101 6/j.socscimed.2013.08.018.

8. Locher JL, Ritchie CS, Roth DL, Baker PS, Bodner EV, Allman RM. Social isolation, support, and capital and nutritional risk in an older sample: ethnic and gender differences. Soc Sci Med. 2005;60(4):747-61. https://doi.org/10.1 016/j.socscimed.2004.06.023.

9. Hawryluck L, Gold WL, Robinson S, Pogorski S, Galea S, Styra R. SARS control and psychological effects of quarantine, Toronto, Canada. Emerg Infect Dis. 2004;10(7):1206-12. https://doi.org/10.3201/eid1007.030703. 
10. Jacka FN, Pasco JA, Mykletun A, Williams LJ, Hodge AM, O'Reilly SL, et al. Association of Western and Traditional Diets with Depression and anxiety in women. Am J Psychiatr. 2010;167(3):305-11. https://doi.org/10.1176/appi.a jp.2009.09060881.

11. Hoare E, Millar L, Fuller-Tyszkiewicz M, Skouteris H, Nichols M, Malakellis M, et al. Depressive symptomatology, weight status and obesogenic risk among Australian adolescents: a prospective cohort study. BMJ Open. 2016; 6(3):e010072. https://doi.org/10.1136/bmjopen-2015-010072.

12. Huang $Y$, Zhao N. Generalized anxiety disorder, depressive symptoms and sleep quality during COVID-19 outbreak in China: a web-based crosssectional survey. Psychiatry Res. 2020;288:112954.

13. Anat AA, Dubovi I, Ruban A. Differences in mental health and health-related quality of life between the Israeli and Italian population during a COVID-19 quarantine. Qual Life Res Int J Qual Life Asp Treat Care Rehab. 2021;30(6): 1675-84. https://doi.org/10.1007/s11136-020-02746-5.

14. Stanton R, To QG, Khalesi S, Williams SL, Alley SJ, Thwaite TL, et al. Depression, anxiety and stress during COVID-19: associations with changes in physical activity, sleep, tobacco and alcohol use in Australian adults. Int J Environ Res Public Health. 2020;17(11):4065. https://doi.org/10.3390/ijerph1 7114065 .

15. Bentlage E, Ammar A, How D, Ahmed M, Trabelsi K, Chtourou H, et al. Practical Recommendations for Maintaining Active Lifestyle during the COVID-19 Pandemic: A Systematic Literature Review. Int J Environ Res Public Health. 2020;17(17):6265

16. Sun $S$, Lin D, Operario D. Need for a population health approach to understand and address psychosocial consequences of COVID-19. Psychol Trauma Theory Res Pract Policy. 2020;12(S1):S25-s7. https://doi.org/10.1037/ tra0000618.

17. Jain $\mathrm{SH}$, Chandrashekar P. Implementing a targeted approach to social determinants of health interventions. Am J Manag Care. 2020;26(12):502-4. https://doi.org/10.37765/ajmc.2020.88537.

18. Government of Western Australia Department of Health. Western Australia Health and Wellbeing Surveillance System 2020 [Available from: https:// ww2.health.wa.gov.au/Reports-and-publications/Population-surveys.

19. Lovibond SH, Lovibond PF. Manual for the depression anxiety stress scales. 2nd Ed ed. Sydney: Psychology Foundation; 1995.

20. Antony MM, Bieling PJ, Cox BJ, Enns MW, Swinson RP. Psychometric properties of the 42-item and 21-item versions of the depression anxiety stress scales in clinical groups and a community sample. Psychol Assess. 1998;10(2):176-81. https://doi.org/10.1037/1040-3590.10.2.176.

21. Kessler RC, Andrews G, Colpe LJ, Hiripi E, Mroczek DK, Normand SL, et al. Short screening scales to monitor population prevalences and trends in non-specific psychological distress. Psychol Med. 2002;32(6):959-76. https:// doi.org/10.1017/S0033291702006074.

22. Australian Bureau of Statistics. Kessler psychological distress scale-10 (K10) 2019 [Available from: https://www.abs.gov.au/ausstats/abs@.nsf/Lookup/ by\%20Subject/4363.0 2014-15 Main\%20Features Kessler\%20Psychologica 1\%20Distress\%20Scale-10\%20(K10) 35.

23. Furukawa TA, Kessler RC, Slade T, Andrews G. The performance of the K6 and K10 screening scales for psychological distress in the Australian National Survey of mental health and well-being. Psychol Med. 2003;33(2): 357-62. https://doi.org/10.1017/S0033291702006700.

24. Hughes ME, Waite LJ, Hawkley LC, Cacioppo JT. A short scale for measuring loneliness in large surveys: results from two population-based studies. Res Aging. 2004;26(6):655-72. https://doi.org/10.1177/0164027504268574.

25. Karania VK. Measuring the level of loneliness in England: combining responses from a single-item direct loneliness question and the UCLA 3item loneliness scale. AgeUK; 2020.

26. Lenhard W, Lenhard A. Calculation of Effect Sizes 2016 [Available from: https://www.psychometrica.de/effect_size.html.

27. Patton MQ. Qualitative Research \& Evaluation Methods Integrating Theory and practice 4th Ed ed. Thousand Oaks: Sage Publications; 2014.

28. Epidemiology Branch. COVID-19 in Western Australia, bulletin 1: the impact on lifestyle. Perth: WA Department of Health; 2020. Available from: https:// www.healthywa.wa.gov.au/ /media/Corp/Documents/Reports-and-publica tions/COVID19-in-Western-Australia/COVID19-in-WA-Bulleltin-1-Impact-onLifestyle.pdf

29. Epidemiology Branch. COVID-19 in Western Australia bulletin 2: the impact on mental health 2021 [Available from: https://ww2.health.wa.gov.au/-/ media/Corp/Documents/Reports-and-publications/COVID19-in-Western-A ustralia/COVID19-in-WA-Bulletin-2-Impact-on-mental-health.pdf].
30. Scerri J, Sammut A, Cilia Vincenti S, Grech P, Galea M, Scerri C, et al. Reaching out for help: calls to a mental health helpline prior to and during the COVID-19 pandemic. Int J Environ Res Public Health. 2021;18(9):4505. https://doi.org/10.3390/ijerph18094505.

31. Tomaz SA, Coffee P, Ryde GC, Swales B, Neely KC, Connelly J, et al. Loneliness, Wellbeing, and Social Activity in Scottish Older Adults Resulting from Social Distancing during the COVID-19 Pandemic. Int J Environ Res Public Health. 2021;18(9):4517.

32. Bao L, Li WT, Zhong BL. Feelings of loneliness and mental health needs and services utilization among Chinese residents during the COVID-19 epidemic. Glob Health. 2021;17(1):51. https://doi.org/10.1186/s12992-021-00704-5.

33. Henssler J, Stock F, van Bohemen J, Walter H, Heinz A, Brandt L. Mental health effects of infection containment strategies: quarantine and isolation-a systematic review and meta-analysis. Eur Arch Psychiatry Clin Neurosci. 2021;271(2):223-34. https://doi.org/10.1007/s00406-020-01196-x.

34. Lee SL, Pearce E, Ajnakina O, Johnson S, Lewis G, Mann F, et al. The association between loneliness and depressive symptoms among adults aged 50 years and older: a 12-year population-based cohort study. Lancet Psychiatry. 2021;8(1):48-57. https://doi.org/10.1016/S2215-0366(20)30383-7.

35. Mautong H, Gallardo-Rumbea JA, Alvarado-Villa GE, Fernández-Cadena JC, Andrade-Molina D, Orellana-Román CE, et al. Assessment of depression, anxiety and stress levels in the Ecuadorian general population during social isolation due to the COVID-19 outbreak: a cross-sectional study. BMC Psychiatry. 2021;21(1):212. https://doi.org/10.1186/s12888-021-03214-1.

36. Del Río-Casanova L, Sánchez-Martín M, García-Dantas A, González-Vázquez A, Justo A. Psychological Responses According to Gender during the Early Stage of COVID-19 in Spain. Int J Environ Res Public Health. 2021;18(7):3731.

37. WorldOMeter. COVID-19 Coronavirus pandemic 2021 [Available from: https://www.worldometers.info/coronavirus/\#countries.

38. Saadatian-Elahi M, Facy F, Del Signore C, Vanhems P. Perception of epidemic's related anxiety in the general French population: a crosssectional study in the Rhône-Alpes region. BMC Public Health. 2010;10(1): 191. https://doi.org/10.1186/1471-2458-10-191.

39. Jalloh MF, Li W, Bunnell RE, Ethier KA, O'Leary A, Hageman KM, et al. Impact of Ebola experiences and risk perceptions on mental health in Sierra Leone, July 2015. BMJ Glob Health. 2018;3(2):e000471. https://doi.org/10.1136/ bmigh-2017-000471.

40. Eastman MR, Finlay JM, Kobayashi LC. Alcohol use and mental health among older American adults during the early months of the COVID-19 pandemic. Int J Environ Res Public Health. 2021;18(8):4222. https://doi.org/1 0.3390/ijerph18084222.

41. Pabst A, Bollen Z, Creupelandt C, Fontesse S, Orban T, de Duve M, et al. Alcohol consumption changes during the first COVID-19 lockdown: an online population survey in a convenience sample of French-speaking Belgian residents. Psychiatry Res. 2021;300:113938. https://doi.org/10.1016/j. psychres.2021.113938.

42. Manthey J, Kilian C, Carr S, Bartak M, Bloomfield K, Braddick F, et al. Use of alcohol, tobacco, cannabis, and other substances during the first wave of the SARS-CoV-2 pandemic in Europe: a survey on 36,000 European substance users. Subst Abuse Treat Prev Policy. 2021;16(1):36. https://doi. org/10.1186/s13011-021-00373-y.

43. Koopmann A, Georgiadou E, Reinhard I, Müller A, Lemenager T, Kiefer F, et al. The effects of the lockdown during the COVID-19 pandemic on alcohol and tobacco consumption behavior in Germany. Eur Addict Res. 2021;27(4):1-15. https://doi.org/10.1159/000515438.

44. Rossow I, Bye EK, Moan IS, Kilian C, Bramness JG. Changes in Alcohol Consumption during the COVID-19 Pandemic-Small Change in Total Consumption, but Increase in Proportion of Heavy Drinkers. Int J Environ Res Public Health. 2021;18(8):4231.

45. Savic M, Room R, Mugavin J, Pennay A, Livingston M. Defining "drinking culture": a critical review of its meaning and connotation in social research on alcohol problems. Drugs EducPrevent Policy. 2016;23(4):270-82.

46. Folk AL, Wagner BE, Hahn SL, Larson N, Barr-Anderson DJ, Neumark-Sztainer D. Changes to Physical Activity during a Global Pandemic: A Mixed Methods Analysis among a Diverse Population-Based Sample of Emerging Adults in the U.S. Int J Environ Res Public Health. 2021;18(7):3674.

47. Joseph RP, Pituch KA, Guest MA, Maxfield M, Peckham A, Coon DW, et al. Physical Activity Among Predominantly White Middle-Aged and Older US Adults During the SARS-CoV-2 Pandemic: Results From a National Longitudinal Survey. Front Public Health. 2021;9:652197. 
48. Petersen JA, Naish C, Ghoneim D, Cabaj JL, Doyle-Baker PK, McCormack GR. Impact of the COVID-19 Pandemic on Physical Activity and Sedentary Behaviour: A Qualitative Study in a Canadian City. Int J Environ Res Public Health. 2021:18(9):4441.

49. Alzahrani $H$, Alshehri F, Alsufiany M, Allam HH, Almeheyawi R, Eid MM, et al. Impact of the 2019 Coronavirus disease pandemic on health-related quality of life and psychological status: the role of physical activity. Int J Environ Res Public Health. 2021;18(8). https://doi.org/10.3390/ijerph18083992.

50. Hamer M, Stamatakis E, Steptoe A. Dose-response relationship between physical activity and mental health: the Scottish health survey. Br J Sports Med. 2009:43(14):1111-4. https://doi.org/10.1136/bjsm.2008.046243.

51. Bennett G, Young E, Butler I, Coe S. The Impact of Lockdown During the COVID-19 Outbreak on Dietary Habits in Various Population Groups: A Scoping Review. Front Nutr. 2021;8:626432.

52. O'Neil A, Quirk SE, Housden S, Brennan SL, Williams LJ, Pasco JA, et al. Relationship between diet and mental health in children and adolescents: a systematic review. Am J Public Health. 2014;104(10):e31-42. https://doi.org/1 0.2105/AJPH.2014.302110

53. Lai JS, Hiles S, Bisquera A, Hure AJ, McEvoy M, Attia J. A systematic review and meta-analysis of dietary patterns and depression in communitydwelling adults. Am J Clin Nutr. 2014;99(1):181-97. https://doi.org/10.3945/a jen.113.069880.

54. Government of Western Australia. WA Health Promotion Strategic Framework 2021 [Available from: https:/ww2.health.wa.gov.au/Reports-andpublications/WA-Health-Promotion-Strategic-Framework.

55. Government of Western Australia Department of Health. COVID-19 public information campaign 2020 [Available from: https://ww2.health.wa.gov.au/A rticles/A_E/Campaign-COVID-19.

\section{Publisher's Note}

Springer Nature remains neutral with regard to jurisdictional claims in published maps and institutional affiliations.

Ready to submit your research? Choose BMC and benefit from:

- fast, convenient online submission

- thorough peer review by experienced researchers in your field

- rapid publication on acceptance

- support for research data, including large and complex data types

- gold Open Access which fosters wider collaboration and increased citations

- maximum visibility for your research: over $100 \mathrm{M}$ website views per year

At $\mathrm{BMC}$, research is always in progress.

Learn more biomedcentral.com/submissions 